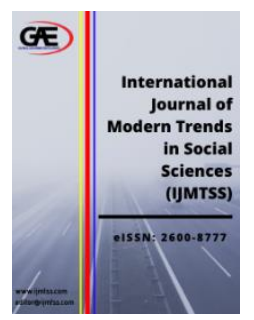

\author{
INTERNATIONAL JOURNAL OF \\ MODERN TRENDS IN \\ SOCIAL SCIENCES \\ (IJMTSS) \\ WWW.ijmtss.com
}

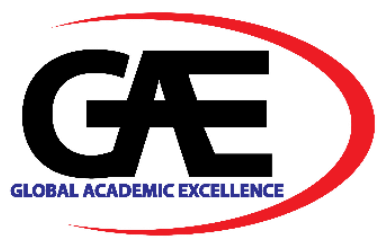

\title{
FACTORS AFFECTING NON-ADHERENCE TO TREATMENT OF HEMODIAL YSIS PATIENTS IN MAKKAH CITY, KINGDOM OF SAUDI ARABIA
}

\author{
Ghanim. Hamid. Al-Khattabi ${ }^{1^{*}}$
}

1 Consultant Doctor in Preventive Medicine and Public Health, Epidemiologist, Ministry of Health, Makkah City, Kingdom of Saudi Arabia

Email: dralkhattabi@gmail.com

* Corresponding Author

\section{Article Info:}

Article history:

Received date: 14.09 .2020

Revised date: 30.09 .2020

Accepted date: 20.10 .2020

Published date: 03.12.2020

\section{To cite this document:}

Al-Khattabi, G. H. (2020). Factors Affecting Non-Adherence to Treatment of Hemodialysis Patients in Makkah City, Kingdom of Saudi Arabia. International Journal of Modern Trends in Social Sciences, 3 (14), 21-38

DOI: $10.35631 /$ IJMTSS.314002

This work is licensed under $\underline{\mathrm{CC} B Y} 4.0$ (a)

\begin{abstract}
:
Background: Adherence of hemodialysis patients to medical instructions is considered crucial for a longer life expectancy and better quality of life. There is solid evidence that non-adherence of end-stage renal disease patients correlates with morbidity and mortality, is the norm for dialysis patients rather than the exception, multiple factors influence it and inconsistencies exist in findings of the relationships between risk factors and non-adherence. Despite the importance of this topic, there is remarkable paucity in the studies which identify factors associated with non-adherence in hemodialysis patients in Saudi Arabia. Objectives: To determine factors related to non-adherence to fluid, diet, medication, and hemodialysis sessions among hemodialysis patients in Makkah. Materials and Methods: The current study is a cross-sectional one, where a sample of 361 hemodialysis patients was selected randomly from hemodialysis centers in three governmental hospitals in Makkah in order to determine factors related to their non-adherence to treatment by using an endstage renal disease-adherence questionnaire (ESRD-AQ) in addition to clinical examination and laboratory investigation for other data. Results: Younger $(<30$ years), unmarried, non-Saudis, those with chronic diseases other than hypertension and diabetes mellitus, and those with long dialysis duration (60+ months) were found more likely to be non-adherent to the fluid. Females patients and those with short dialysis duration ( $<60$ months) were found more likely to be non-adherent to diet and medications, respectively. Conclusion: Patients who had factors associated with non-adherence deserve special attention and support to improve their adherence behavior. The findings from this study can be used as a base for designing an intervention aimed to increase the adherence to treatment in end-stage renal disease patients who are undergoing hemodialysis in order to decrease the direct and indirect cost that appear as a consequence of non-adherence.
\end{abstract}


Keywords:

Hemodialysis, Non-Adherence, Factors, Makkah, Treatment, Saudi Arabia

\section{Introduction}

Adherence (or compliance) is a dynamic, relative, complex, and multidimensional concept ${ }^{\text {(KM, }}$ MH, JP, \& NW, 1982; NG, 2001; Rosner, 2006) which is defined as “the extent to which a person's behavior such as taking medications, following diets, or executing lifestyle changes coincide with medical or health advice"(Organization, 2003)(p.17).

Poor adherence to complex multimodal therapies is a widely recognized problem in the daily care of hemodialysis (HD) patients, which contribute to excess morbidity and mortality of this population $(\mathrm{S} . \mathrm{H}, \mathrm{B}, \& \mathrm{H}, 2009)$. This argument comes in the time where the incidence of chronic renal diseases is reported to be rising globally by about $6 \%$ annually (DL et al., 2004), and the incidence of dialysis patients is increasing by around 7\% worldwide ${ }^{\text {(Lacson Jr \& Hakim, 2011) }}$.In Saudi Arabia, according to the latest dialysis statistics performed by the Saudi Center for Organ Transplantation (SCOT) in 2012; there was a total of 14,171 patients on dialysis, out of them there were $12,844(90.6 \%)$ treated by HD while the rest $(1,327 ; 9.4 \%)$ were treated by peritoneal dialysis (PD); the overall mortality rate accounted for $(11.6 \%)^{\text {(Transplantation, 2012). }}$.

There is a solid evidence that non-adherence of ESRD patients' correlates with morbidity and mortality (S. H et al., 2009), Specifically, the literatures indicated that skipping treatment and poor dietary adherence are strongly associated with greater risk for mortalities among dialysis

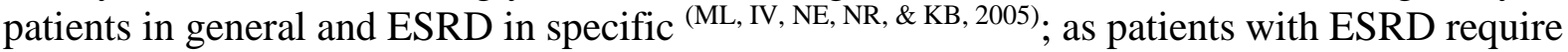
lifetime commitment to their treatments including renal replacement therapy (RRT) and the medical treatments for their underlying disease for survival, and are faced with a lot of challenges related to their adherence to treatment (NKF). 2002) Despite severe consequences, noncompliance with their medical regimen is the norm for dialysis patients rather than the exception (SI, N, \& NP, 1993).

HD patients are well suited for studying non-adherence because they have a number of features that characterizes their lifestyle and put them at an increased risk of non-adherence including prolonged, intensive treatment and their medical regimens are clear cut and easily determined with objective measures (SI et al., 1993). Despite these signaling facts and figures, the reviewed literatures indicated that reports concerning adherence vary widely and the rates to attendance at HD, medications, fluid and diet restrictions range from up to $100 \%$ to as low as $17.6 \%$ (CL, M, V, \& F, 2004; Hecking et al., 2004; SH \& A, 2002). These wide ranges of adherence behavior in the literature is most likely related to different population being studied, inconsistency in the measures used to investigate adherence behavior of patient and lack of clinically relevant operational definitions of non-adherence (Chan, Zalilah, \& Hii, 2012; Kim, 2010). Moreover, it had been reported that there is paucity of studies which included all four aspects of the HD regimen, namely adherence related to fluid restrictions, dietary guidelines, medication, and dialysis appointments ${ }^{\text {(Denhaerynck }}$ et al., 2007).

According to the World Health Organization (WHO) there are 5 categories of factors influencing the degree of adherences of the patients; they include (i) socioeconomic factors, (ii) therapy- related factors, (iii) patient-related factors, (iv) condition- related factors and (v) 
health care system-related factors ${ }^{(\mathrm{PV} \& \mathrm{E}, 2003)}$.In this respect, it was found that adherence is increased significantly with the higher percentage of highly trained staff and presence of a dietitian (Saran et al., 2003).

Despite the importance of this topic, there is remarkable paucity in the studies which identify factors associated with non-adherence in HD patients in Saudi Arabia. (Eida, 2010).

The current study aims at ameliorating the adverse consequences of non-adherence among HD patients through providing scientific background and better understanding for the factors associated with non-adherence, so decrease the direct and indirect cost that appear as a consequence of non-adherence. The objectives of current study were to determine factors related to non-adherence to fluid, diet, medication and HD sessions among HD patients in Makkah city.

\section{Literature Review}

Lacks of adequate knowledge, inadequate self-efficacy skills, forgetfulness and financial constraints were the major perceived barriers towards better compliance to fluid, dietary, medication and dialysis ${ }^{(\text {Chan et al., 2012; Green et al., 2013) }}$. In a study conducted in Malaysia it was found that younger, male, working patients and those with longer duration on HD were found more likely to be noncompliant ${ }^{(\text {Chan et al., 2012) }}$.In another study done in Turkey, it was found that age, marital status and family support were also main variables affecting diet non-adherence; the results of this study showed that non-adherence was more common among younger, married

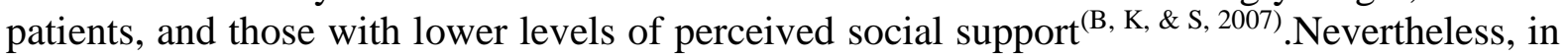
this respect, it had been found that although social support is important for increasing adherence, yet, it was found that when diet is prepared by someone else in the family, patients are more likely to be noncompliant ${ }^{\text {(Lee } \& \text { Molassiotis, 2002) }}$.

Also, adherence was found to be positively associated with higher educational level (Christiane Kugler, Maeding, \& L.Russell, 2011) and higher monthly income ${ }^{(Y \& \text { LS, 2010) }}$. Other studies have shown that adherence to treatment in patients receiving HD is influenced by personal characteristics such as age, gender, smoking, HD duration and comorbidity (C Kugler, Vlaminck, Haverich, \& Maes, 2005; NG, 2001; Takaki et al., 2003).

Also, it was found that the need to change eating habits and inability to resist favorite foods in addition to complexity of dietary recommendation were the major factors cited for dietary noncompliance, and lack of knowledge about fluid management was the major factor for fluid non-

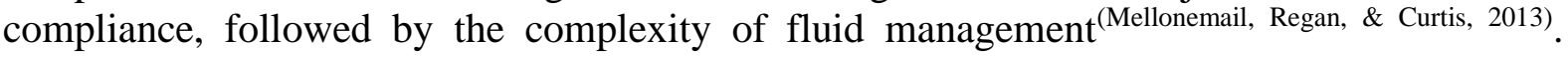
Moreover, it was addressed that the majority of the patients reported they had difficulty adhering to phosphate binder per se due to its associated side effects such as constipation and the unpleasant experience to take large quantities with meals. The same study indicated that some patients had difficulty to comply with dialysis attendance due to financial constraint and lacks of transportation facility (Latham, 1998). Studies showed that compliance to treatment is positively associated with knowledge of the patients about their diet and better attitude towards compliance in addition to perceiving lower barriers (LK et al., 2001). The role of the health team was also investigated to examine its impact on the level of adherence of patients, where it was reported that better communication between physicians and their patients lead to better adherence ${ }^{\text {(Zolnierek \& DiMatteo, 2009). }}$ 
In summary, the literature indicates that adherence is a difficult issue for staff and patients, and multiple factors influence non-adherence to treatment. However, inconsistencies exist in findings about the relationships between risk factors and non-adherence. Most studies have also been conducted in Western countries and none have been done to examine the nonadherence in Saudi patients receiving HD.

\section{Materials and Methods}

This study was a cross-sectional one conducted in three HD centers at three major governmental hospitals in Makkah city which is located in the Western region of Saudi Arabia. The HD machines are always busy through the year with four shifts daily. Sometimes a fifth shift has to be arranged to overcome the heavy workload with large influx of patients during the Holy months of Ramadan and Hajj due to a large number of visitors from outside the city of Makkah and there is an arrangement for visitors who have ESRD and need dialysis to do it in governmental hospitals. Small HD units are also available in other governmental and private hospitals, which accommodate for only a small percentage of patients.

The study population represents patients registered in the three HD centers present in three major governmental hospitals in Makkah city. Their total number was estimated to be around 2000 patients at the time of the study; they included all patients with ESRD requiring HD and they are all registered in the HD units of kidney centers. Patients at the HD centers in the three hospitals undergo HD for an average of 3 times a week, with a small percentage undergoing HD only twice a week. The HD sessions usually take place in four shifts, from 7:30 A.M to 10:30 A.M, from 11:00 A.M to 2:00 P.M, from 2:30 P.M to 5:30 P.M and from 6:00 P.M to 9:00 P.M.

The sample size needed for estimating prevalence of adherence and exploring factors associated with non-adherence was calculated by using Epi-Info program version 6.04; the required sample size was 385 patients.

The responded who completed the participation accounted for 361; making a response rate of 93.8\%. Inclusion criteria were any patient, conscious, understands, able to give an informed consent (if the patient was less than 18 years, the consent was taken from his parents) and regular on HD.

Stratified sampling was conducted to ensure representativeness of male and female patients. Stratification was based on the available list of patients at each HD center in each hospital. This list cover patients from all wards, including male and female wards, the isolation section, both hepatitis $\mathrm{C}$ positive and negative patients and at different times of the day.

As the number of patients who were available at the time of the study accounted for 770 patients, an estimated sample size was 385 which represented one half of the patients; therefore, the estimation designated sample in each place was half of available listed patients.

The allocation of patients from each list was done by systematic sampling selecting every second patient in each list. There were separate lists for males and females which facilitated allocation of the sample by gender.

Adherence to treatment regimens in patients with ESRD was measured by a variety of methods, with no one method being superior (Denhaerynck et al., 2007), however, the (ESRD-AQ) was 


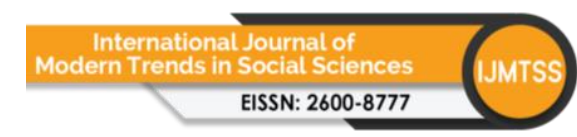

Volume 3 Issue 14 (December 2020) PP. 21-38

DOI 10.35631/IJMTSS.314002

considered the most appropriate for evaluating treatment adherence or non-adherence in patients with ESRD on maintenance HD. The ESRD-AQ instrument is a self-administrated questionnaire consists of 46 items; it addresses all components of adherence behaviors of patients with ESRD, and it was found to be valid and reliable. It is easy to administer; its

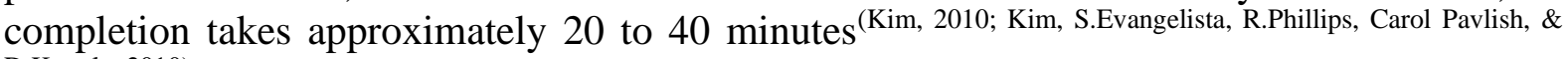
D.Kopple, 2010).

The questionnaire measures treatment adherence behaviors in four dimensions: HD attendance, medication use, fluid restrictions and diet restrictions recommendations. It is divided into five sections; the first section includes general information about patients' ESRD and RRT related history (5 items), and the remaining four sections ask about treatment adherence to HD treatment (14 items), medications ( 9 items), fluid restrictions (10 items), and diet restrictions recommendations ( 8 items). These four final sections directly measure adherence behaviors $(14,17,18,26,31$, and 46), and patients' knowledge and perceptions about treatment $(11,12$, $22,23,32,33,41$, and 42). Responses to the ESRD-AQ utilize a combination of Likert scales and multiple-choice items, as well as "yes/no" answer format. The adherence behavior subscale was scored by summing the responses to questions $14,17,18,26$, and 46 . The weighting system for scores was determined based on the degree of importance relevant to clinical outcome of each dimension. For example, missing or shortening HD has been reported to have a stronger association with mortality of patients with ESRD than other components of adherence behavior; therefore, it was given more weight in computing the adherence scores. In addition, the ESRD-AQ adjusts scores for question numbers 14 ("During the last month, how many complete dialysis treatments did you miss?"), 18 ("During the last month, when your dialysis treatment was shortened, what was the average numbers of minutes?"), and 26 ("During the past week, how often have you missed your prescribed medicines?") depending on the reasons for not adhering. For example, patients with medical reasons for missing or shortening the HD treatment (such as having HD access problems or physical symptoms during HD) obtained a full score (see appendix A). The attitude/perception subscale was scored by summing the responses to questions $11,12,22,23,32,33,41$, and 42 . The remaining questions obtain information about patients' ESRD and RRT related history. The ESRD-AQ was designed such that higher scores indicate better adherence ${ }^{(\text {Kim et al., 2010). }}$

The original English version of questionnaire was translated to Arabic then it was back translated to ensure lexical equivalence. Additionally, it was subjected to validity testing after being translated into Arabic language.

A set of a structured list was developed by the researcher to ascertain information on patients' demographic characteristics and factors associated with non-adherence of patients and was translated into Arabic and reviewed by consultant of family medicine, consultant of community medicine and nephrology consultant; and was added to the End-Stage Renal DiseaseAdherence Questionnaire (ESRD-AQ).

Each patient's adherence behavior was rated based on IDWGs, dialysis attendance, serum potassium and phosphorous levels over the previous month. These criteria were used separately to distinguish between adherent and non-adherent patients (Saran et al., 2003).

Dry weight (weight at the end of dialysis treatment) which is taken as the lowest tolerable weight at the end of dialysis treatment without the development of symptoms or hypotension, and the inter dialytic weight gain (IDWG) is calculated as the difference between the patient's Copyright (C) GLOBAL ACADEMIC EXCELLENCE (M) SDN BHD - All rights reserved 
weight obtained at the onset of a dialysis treatment and the weight obtained at the end of the previous dialysis $^{\text {(Leggat Jr et al., 1998). }}$

The clinical measurements included biological measurements which included in addition to interdialytic weight gain (IDWG), biochemical markers which included pre-HD serum potassium or phosphorous levels.

Patients were considered non-adherent in the following situations (JM, M, R, P, \& R, 2005; Kim et al., 2010; Leggat Jr et al., 1998):

1. If IDWGs were greater than $5.7 \%$ higher than the previous weight more than once weekly (for non-adherence to fluid restrictions) (the last cut-off was based on a $>4 \mathrm{~kg}$ IDWG in a $70 \mathrm{~kg}$ patient).

2. If they skipped one or more sessions of HD per month, or shortened one or more sessions by more than 10 minutes per month (for non-adherence to HD). A session missed because of hospitalization was not considered non-adherence.

3. If serum potassium was higher than $6.0 \mathrm{mmol} / \mathrm{L}(>6.0 \mathrm{mEq} / \mathrm{L}$ ) (for non-adherence to diet restrictions) on monthly laboratory results.

4. If serum phosphorus was higher than $7.5 \mathrm{mg} / \mathrm{dL}(>2.4 \mathrm{mmol} / \mathrm{L})$, (for non-adherence to medication).

Upon arrival to the dialysis centers, the physicians in charge were contacted and the researcher used to present the study design and explain the purpose of the research to the HD staff. Information regarding the HD center was obtained from the chief HD nurse. According to selection and inclusion criteria, designated patients were invited to participate in the study after explaining to them the purpose of the study.

Medical files of the patient were examined to check the weight of patients pre HD, weight of patients post HD (dry weight), number of co-morbid diseases and the presence of chronic disease (such as DM, HTN), psychiatric diseases, hospitalization history, kidney transplant history, causes of kidney failure, hepatitis profile, potassium and phosphorus level, for how long is he or she on dialysis, number of daily tablet, others... These information were available for every patient as they are doing a monthly blood test examination pre and post HD session to evaluate the level of potassium, phosphorus and others chemical indicators. By asking patients, nurses and confirmed by reviewing patients' files, the researcher could identify how many times patients skipped and shortened their HD session per month. These information were used to specify adherence and non-adherence according to definitions disclosed above.

Weight for each patient was measured before and after each HD sessions by well-trained nurses. The patient's weight at the beginning of dialysis session was subtracted from the weight at the end of previous dialysis session (dry weight) to calculate the interdialytic weight gain (IDWG); then this IDWG is divided by weight at the end of previous dialysis session (dry weight) to get IDWG percentage. If IDWG percentage was more than $5.7 \%$ more than once weekly, then patient was considered as non-adherence to fluid restriction recommendations.

A standard electronic weighing chair was used to obtain the weight. The scale was placed on a hard floor surface. Participants were asked to remove their heavy outer garments; female patients were weighed with Abaya (ladies body cover), and Abaya was weighed and its weight was subtracted from the total. Weight was measured in all participants and taken to the nearest Copyright (C) GLOBAL ACADEMIC EXCELLENCE (M) SDN BHD - All rights reserved 
$0.1 \mathrm{~kg}$ using weighing scale. The scale was calibrated at the beginning and end of each examining day. The scale was checked using the standardized weights and calibration was corrected if the error was greater than $0.1 \mathrm{~kg}$.

Statistical Package for Social Science (SPSS) program, version 20 was used for statistical analysis of data. The level of statistical significance was set at $\mathrm{P}<0.05$ throughout the study.

\section{Results}

The study included 361 patients. The majority of them (78.9\%) aged $<65$ years, with a mean age of 50.1 \pm 15.8 years. There was almost equal distribution of males and females with an overwhelming majority of Saudis (93.9\%). About two thirds of them were married $(62.3 \%)$ and around one third $(31.3 \%)$ were illiterate. The great majorities $(88.9 \%)$ were unemployed and almost two thirds of the patients $(60.1 \%)$ had monthly income between 1000 and 3000 SR.

The most commonly identified causes of renal failure were diabetes mellitus (23\%) and hypertension $(21.9 \%)$. On the same line, it was found that the overwhelming majorities of the patients $(93.9 \%)$ were currently hypertensive and a considerable proportion $(39.6 \%)$ were currently diabetic and almost one half (49.9\%) were positive for HCV. One half of the patients $(50.3 \%)$ were on dialysis for 60 months or more and the majority $(77 \%)$ had previous history of hospitalization. Clinically, the average number of co-morbidities accounted for 3.0 diseases; the median IDWG was $2.0 \mathrm{~kg}$; the average number of daily tablet(s) taken by patients was 5.0. The mean levels of pre- HD serum potassium $\left(\mathrm{K}^{+}\right)$and phosphorus $(\mathrm{po} 4)$ were $5.1(0.9) \mathrm{mmol} / \mathrm{L}$ and 5.3(1.8) $\mathrm{mg} / \mathrm{dl}$; respectively.

A relatively low adherence to regular attendance to dialysis sessions $(56 \%)$ was reported, the great majority of patients were found to be adherent to other adherence behavior namely: diet, fluid restrictions and medications.

Table 1: Adherence of The Patients to Fluid Restriction Recommendations According to Their Demographic Characteristics

\begin{tabular}{|c|c|c|c|c|c|c|c|}
\hline \multirow{3}{*}{ Characteristics } & \multicolumn{7}{|c|}{ Adherence to Fluid Restriction } \\
\hline & & \multicolumn{2}{|c|}{ YES } & \multicolumn{2}{|c|}{ NO } & \multirow[t]{2}{*}{$X^{2}$} & \multirow[t]{2}{*}{$\mathbf{P}$} \\
\hline & & No & $\%$ & No & $\%$ & & \\
\hline \multirow[t]{2}{*}{ Gender } & Males & 154 & 89.5 & 18 & 10.5 & 0.948 & 0.330 \\
\hline & Females & 162 & 86.2 & 26 & 13.8 & & \\
\hline \multirow[t]{2}{*}{ Nationality } & Saudi & 300 & 88.8 & 38 & 11.2 & Fisher & 0.039 \\
\hline & Non-Saudi & 16 & 72.7 & 6 & 27.3 & & \\
\hline \multirow[t]{3}{*}{ Age } & $<30$ Years & 28 & 60.9 & 18 & 39.1 & 36.262 & $<0.001$ \\
\hline & $30-<60$ Years & 183 & 90.6 & 19 & 9.4 & & \\
\hline & $60+$ Years & 105 & 93.8 & 7 & 6.3 & & \\
\hline Age Mean+SD & & $51.3 \pm 15.2$ & & & \pm 17.2 & & $<0.001 *$ \\
\hline \multirow[t]{4}{*}{ Marital Status } & Married & $20 \overline{0}$ & 92.9 & 16 & 7.1 & 19.203 & $<0.001$ \\
\hline & Single & 57 & 74.0 & 20 & 26.0 & & \\
\hline & Divorced & 16 & 88.9 & 2 & 11.1 & & \\
\hline & Widowed & 35 & 85.4 & 6 & 14.6 & & \\
\hline \multirow[t]{2}{*}{ Educational Level } & Illiterate & 100 & 88.5 & 13 & 11.5 & 1.675 & 0.247 \\
\hline & Primary School & 79 & 89.8 & 9 & 10.2 & & \\
\hline
\end{tabular}




\begin{tabular}{llcccccc} 
& & & \multicolumn{5}{c}{ DOI 10.35631/IJMTSS.314002 } \\
& Intermediate School & 51 & 89.5 & 6 & 10.5 & & \\
& Secondary School & 54 & 84.4 & 10 & 15.6 & & \\
& University & 32 & 84.2 & 6 & 15.8 & & \\
Employment Status & Employed & 37 & 92.5 & 3 & 7.5 & Fisher & 0.486 \\
& Not Employed & 279 & 87.2 & 41 & 12.8 & & \\
Monthly Income & $<\mathbf{1 0 0 0}$ SR & 38 & 82.6 & 8 & 17.4 & & \\
& $\mathbf{1 0 0 0 - < 3 0 0 0 ~ S R ~}$ & 189 & 87.5 & 27 & 12.5 & 2.600 & 0.457 \\
& $\mathbf{3 0 0 1 - < 6 0 0 0 ~ S R}$ & 53 & 93.0 & 4 & 7.0 & & \\
\hline
\end{tabular}

*Based on Independent Sample T Test.

Table 2: Adherence of The Patients to Fluid Restriction Recommendations According to Their Clinical Background

Adherence to Fluid Restriction

\begin{tabular}{|c|c|c|c|c|c|c|c|}
\hline \multicolumn{2}{|l|}{ Characteristics } & \multicolumn{2}{|c|}{ YES } & \multicolumn{2}{|c|}{ NO } & \multirow[t]{2}{*}{$X^{2}$} & \multirow[t]{2}{*}{$\mathbf{P}$} \\
\hline & & No & $\%$ & No & $\%$ & & \\
\hline \multirow[t]{2}{*}{ Duration of Dialysis } & $<60$ Months & 164 & 92.1 & 14 & 7.9 & 6.534 & 0.011 \\
\hline & 60+ Months & 149 & 83.2 & 30 & 16.8 & & \\
\hline \multirow{3}{*}{$\begin{array}{l}\text { Main Cause } \\
\text { Renal } \\
\text { Failure }\end{array}$} & Hypertension & 72 & 92.3 & 6 & 7.7 & 6.182 & 0.045 \\
\hline & Diabetes Mellitus & 77 & 92.8 & 6 & 7.2 & & \\
\hline & Others & 167 & 83.9 & 32 & 16.1 & & \\
\hline \multirow{2}{*}{$\begin{array}{l}\text { Previous Kidney } \\
\text { Transplant }\end{array}$} & Yes & 20 & 90.9 & 2 & 9.1 & Fisher & 0.481 \\
\hline & No & 296 & 87.6 & 42 & 12.4 & & \\
\hline \multirow{2}{*}{$\begin{array}{l}\text { Diagnosed With } \\
\text { Psychiatric Illness }\end{array}$} & Yes & 33 & 89.2 & 4 & 10.8 & Fisher & 0.517 \\
\hline & No & 283 & 87.6 & 40 & 12.4 & & \\
\hline
\end{tabular}

Table 1 demonstrates that the Saudi patients are significantly more adherent to fluid restriction recommendations $(88.8 \%)$ than the non-Saudis $(72.7 \%)$ with an odds ratio (2.96; 95\% CI: 1.098.02) and older patients are more likely to adhere to fluid restriction than do the younger patients aged <30 years. Meanwhile, it was noted that single patients are significantly less likely to adhere to fluid restriction (74\%) than either the married $(92.9 \%)$, the divorced $(88.9 \%)$ or the widowed $(85.4 \%) \mathrm{p}<0.05$. On the other hand, the table shows that neither the gender, the educational level, the employment status nor the monthly income had significant association with differences in adherence to fluid restriction $\mathrm{p}>0.05$.

Table 2 shows that the longer the duration of dialysis the less likely the patient will be adherent to fluid restriction recommendations, the proportion of adherent patients accounted for $92.1 \%$ for patients who were treated with dialysis for less than 60 months compared to $83.2 \%$ for those who had dialysis for 60 or more months with an odds ratio $(2.36 ; 95 \% \mathrm{CI}$ : 1.20-4.62). Also, it was observed that hypertensive and diabetic patients are significantly more likely to adhere to fluid restriction if compared to those with other chronic diseases; these 
differences are statistically significant $\mathrm{p}<0.05$. On the other hand, it was found that although that patients with previous kidney transplant (90.9\%) and those with psychiatric illnesses $(89.2 \%)$ were more adherent to fluid restrictions, nevertheless, these differences are not statistically significant $\mathrm{p}>0.05$.

Table 3 shows that although the females, the non-Saudis, those aged between $30-<60$ years, married, employed, with lower educational levels and have monthly income between 3000$<6000$ SR had relatively higher level of adherence to dialysis session, however, these differences are not statistically significant $\mathrm{p}>0.05$.

Table 4 shows that there were no significant differences in adherence of the patients to HD sessions according to their clinical characteristics namely: duration of dialysis, main cause of renal failure, previous history of kidney transplant or previous diagnosis of psychiatric illnesses $\mathrm{p}>0.05$.

Table 5 illustrates that the percentage of males who were adherent to dietary restrictions' recommendations $(91.9 \%)$ was significantly higher than that among females $(85.2 \%) \mathrm{p}<0.05$, with an odds ratio (1.96; 95\% CI: 1.00-3.87). Meanwhile, it was noted that the frequency of adherence to dietary restriction was relatively higher among non-Saudi patients, older ages, those who are married, with university qualifications, employed and higher monthly income, nevertheless, these differences are not statistically significant $\mathrm{p}>0.05$.

Table 6 shows that despite of the relatively higher frequency of adherence to diet restrictions' recommendations among patients with duration of dialysis for $<60$ months, hypertensive, patients with previous kidney transplant and those with previous history of psychiatric illnesses, nevertheless, these differences are not statistically significant $p>0.05$.

Table 7 shows that although the females, the non-Saudis, those aged 60+ years, married, with higher educational levels, not employed and have monthly income $<1000$ SR had relatively higher level of adherence to dialysis session, however, these differences are not statistically significant $\mathrm{p}>0.05$.

Table 3: Adherence of The Patients to Hemodialysis Sessions According to Their Demographic Characteristics

\begin{tabular}{|c|c|c|c|c|c|c|c|}
\hline \multirow{2}{*}{ Characteristics } & \multicolumn{7}{|c|}{ Adherence to Hemodialysis Sessions } \\
\hline & & \multicolumn{2}{|c|}{ YES } & \multicolumn{2}{|c|}{ NO } & \multirow[t]{2}{*}{$x^{2}$} & \multirow[t]{2}{*}{$\mathbf{P}$} \\
\hline & & No & $\%$ & No & $\%$ & & \\
\hline \multirow[t]{2}{*}{ Gender } & Males & 96 & 55.8 & 76 & 44.2 & 0.003 & 0.959 \\
\hline & Females & 106 & 56.1 & 83 & 43.9 & & \\
\hline \multirow[t]{2}{*}{ Nationality } & Saudi & 186 & 54.9 & 153 & 45.1 & 2.674 & 0.102 \\
\hline & Non-Saudi & 16 & 72.7 & 6 & 27.3 & & \\
\hline \multirow[t]{3}{*}{ Age } & $<30$ Years & 21 & 45.7 & 25 & 54.3 & 3.136 & 0.208 \\
\hline & $30-<60$ Years & 120 & 59.4 & 82 & 40.6 & & \\
\hline & $60+$ Years & 61 & 54.0 & 52 & 46.0 & & \\
\hline \multirow{4}{*}{$\begin{array}{l}\text { Mean } \pm \text { SD } \\
\text { Marital Status }\end{array}$} & & \multicolumn{2}{|c|}{$51.0 \pm 14.6$} & \multicolumn{2}{|c|}{$48.8 \pm 17.2$} & & 0.192 \\
\hline & Married & 137 & 60.9 & 88 & 39.1 & 7.623 & 0.054 \\
\hline & Single & 34 & 44.2 & 43 & 55.8 & & \\
\hline & Divorced & 11 & 61.1 & 7 & 38.9 & & \\
\hline
\end{tabular}




\begin{tabular}{llllllll} 
& Widowed & 20 & 48.8 & 21 & 51.2 & DOI 10.35631/IJMTSS.314002 \\
Educational Level & Illiterate & 64 & 56.6 & 49 & 43.4 & 4.722 & 0.317 \\
& $\begin{array}{l}\text { Primary School } \\
\text { Intermediate }\end{array}$ & 56 & 62.9 & 33 & 37.1 & & \\
& School & 33 & 57.9 & 24 & 42.1 & & \\
& Secondary School & 32 & 50.0 & 32 & 50.0 & & \\
Employment & University & 17 & 44.7 & 21 & 55.3 & & \\
Status & Employed & 23 & 57.5 & 17 & 42.5 & 0.044 & 0.835 \\
& & & & & & & \\
Monthly Income & Not Employed & 179 & 55.8 & 142 & 44.2 & & \\
& $<\mathbf{1 0 0 0}$ SR & 28 & 60.9 & 18 & 39.1 & 1.132 & 0.769 \\
& $\mathbf{1 0 0 0 - < 3 0 0 0 ~ S R ~}$ & 117 & 53.9 & 100 & 46.1 & & \\
& $\mathbf{3 0 0 1 - < 6 0 0 0 ~ S R ~}$ & 34 & 59.6 & 23 & 40.4 & & \\
\hline & $\mathbf{6 0 0 0 + \text { SR }}$ & 23 & 56.1 & 18 & 43.9 & & \\
\hline
\end{tabular}

*Based on Independent Sample T Test

Table 4: Adherence of The Patients to Hemodialysis Sessions According to Their Clinical Background Adherence to Hemodialysis Sessions

\begin{tabular}{|c|c|c|c|c|c|c|c|}
\hline \multirow[t]{2}{*}{ Characteristics } & & \multicolumn{2}{|c|}{ YES } & \multicolumn{2}{|c|}{ NO } & \multirow[t]{2}{*}{$X^{2}$} & \multirow[t]{2}{*}{$\mathbf{P}$} \\
\hline & & No & $\%$ & No & $\%$ & & \\
\hline \multirow[t]{2}{*}{ Duration of Dialysis: } & $<60$ Months & 95 & 53.4 & 83 & 46.6 & 0.704 & 0.401 \\
\hline & 60+ Months & 104 & 57.8 & 76 & 42.2 & & \\
\hline Main Cause of Renal & Hypertension & 44 & 55.7 & 35 & 44.3 & 0.020 & 0.990 \\
\hline \multirow[t]{2}{*}{ Failure: } & $\begin{array}{l}\text { Diabetes } \\
\text { Mellitus }\end{array}$ & 47 & 56.6 & 36 & 43.4 & & \\
\hline & Others & 111 & 55.8 & 88 & 44.2 & & \\
\hline \multirow{2}{*}{$\begin{array}{l}\text { Previous } \\
\text { Transplant: }\end{array}$} & Yes & 12 & 52.2 & 11 & 47.8 & 0.143 & 0.706 \\
\hline & No & 190 & 56.2 & 148 & 43.8 & & \\
\hline Diagnosed & Yes & 186 & 57.4 & 138 & 42.6 & 2.703 & 0.100 \\
\hline $\begin{array}{l}\text { Psychiatric } \\
\text { Illness: }\end{array}$ & No & 16 & 43.2 & 21 & 56.8 & & \\
\hline
\end{tabular}

Table 5: Adherence of The Patients to Dietary Restrictions According to Their Demographic Characteristics

\begin{tabular}{|c|c|c|c|c|c|c|c|}
\hline \multirow{2}{*}{ Characteristics } & & \multicolumn{5}{|c|}{ Adherence to Dietary Restriction } & \multirow[b]{2}{*}{$\mathbf{P}$} \\
\hline & & \multicolumn{2}{|c|}{ YES } & \multicolumn{2}{|c|}{ NO } & \multirow[t]{2}{*}{$X^{2}$} & \\
\hline & & No & $\%$ & No & $\%$ & & \\
\hline \multirow[t]{2}{*}{ Gender } & Males & 158 & 91.9 & 14 & 8.1 & 3.903 & 0.048 \\
\hline & Females & 161 & 85.2 & 28 & 14.8 & & \\
\hline \multirow[t]{2}{*}{ Nationality } & Saudi & 298 & 87.9 & 41 & 12.1 & Fisher & 0.247 \\
\hline & Non-Saudi & 21 & 95.5 & 1 & 4.5 & & \\
\hline \multirow[t]{3}{*}{ Age } & $<30$ Years & 38 & 82.6 & 8 & 17.4 & 3.071 & 0.215 \\
\hline & $30-<60$ Years & 177 & 87.6 & 25 & 12.4 & & \\
\hline & $60+$ Years & 104 & 92.0 & 9 & 8.0 & & \\
\hline \multicolumn{2}{|l|}{ Mean \pm SD } & & 5.6 & & \pm 17.6 & & 0.275 \\
\hline
\end{tabular}




\begin{tabular}{|c|c|c|c|c|c|c|c|}
\hline \multirow[t]{4}{*}{ Marital Status } & Married & 204 & 90.7 & 21 & 9.3 & $\mathrm{Na}$ & $\mathrm{Na}$ \\
\hline & Single & 64 & 83.1 & 13 & 16.9 & & \\
\hline & Divorced & 16 & 88.9 & 2 & 11.1 & & \\
\hline & Widowed & 35 & 85.4 & 6 & 14.6 & & \\
\hline \multirow[t]{6}{*}{ Educational Level } & Illiterate & 103 & 91.2 & 10 & 8.8 & 4.781 & 0.311 \\
\hline & Primary & 74 & 83.1 & 15 & 16.9 & & \\
\hline & School & & & & & & \\
\hline & $\begin{array}{l}\text { Intermediate } \\
\text { School }\end{array}$ & 50 & 87.7 & 7 & 12.3 & & \\
\hline & $\begin{array}{l}\text { Secondary } \\
\text { School }\end{array}$ & 56 & 87.5 & 8 & 12.5 & & \\
\hline & University & 36 & 94.7 & 2 & 5.3 & & \\
\hline \multirow[t]{2}{*}{ Employment Status } & Employed & 37 & 92.5 & 3 & 7.5 & Fisher & 0.285 \\
\hline & Not Employed & 282 & 87.9 & 39 & 12.1 & & \\
\hline \multirow[t]{4}{*}{ Monthly Income } & $<1000 \mathrm{SR}$ & 39 & 84.8 & 7 & 15.2 & 2.601 & 0.457 \\
\hline & $\begin{array}{l}1000-<3000 \\
\text { SR }\end{array}$ & 190 & 87.6 & 27 & 12.4 & & \\
\hline & $\begin{array}{l}3001-<6000 \\
\text { SR }\end{array}$ & 51 & 89.5 & 6 & 10.5 & & \\
\hline & $6000+\mathrm{SR}$ & 39 & 95.1 & 2 & 4.9 & & \\
\hline
\end{tabular}

*Based on Independent Sample T Test Na: Not Applicable

Table 6: Adherence of The Patients to Dietary Restrictions According to Their Clinical Background

\begin{tabular}{|c|c|c|c|c|c|c|c|}
\hline \multirow{2}{*}{\multicolumn{2}{|c|}{ Characteristics }} & \multicolumn{5}{|c|}{ Adherence to Dietary Restriction } & \multirow{3}{*}{$\mathbf{P}$} \\
\hline & & \multicolumn{2}{|c|}{ YES } & \multicolumn{2}{|c|}{ NO } & \multirow[t]{2}{*}{$X^{2}$} & \\
\hline & & No & $\%$ & No & $\%$ & & \\
\hline \multirow[t]{2}{*}{ Duration of Dialysis: } & $<60$ Months & 161 & 90.4 & 17 & 9.6 & 1.263 & 0.261 \\
\hline & 60+ Months & 156 & 86.7 & 24 & 13.3 & & \\
\hline \multirow{3}{*}{$\begin{array}{l}\text { Main Cause of } \\
\text { Failure: }\end{array}$} & Hypertension & 73 & 92.4 & 6 & 7.6 & 1.632 & 0.422 \\
\hline & $\begin{array}{l}\text { Diabetes } \\
\text { Mellitus }\end{array}$ & 72 & 86.7 & 11 & 13.3 & & \\
\hline & Others & 174 & 87.4 & 25 & 12.6 & & \\
\hline \multirow{2}{*}{$\begin{array}{l}\text { Previous } \\
\text { Transplant: }\end{array}$} & Yes & 21 & 95.5 & 1 & 4.5 & Fisher & 0.247 \\
\hline & No & 298 & 87.9 & 41 & 12.1 & & \\
\hline Diagnosed & Yes & 33 & 89.2 & 4 & 10.8 & Fisher & 0.564 \\
\hline Psychiatric & No & 286 & 88.3 & 38 & 11.7 & & \\
\hline
\end{tabular}


Table 7: Adherence of The Patients to Medication Recommendations According to Their Demographic Characteristics

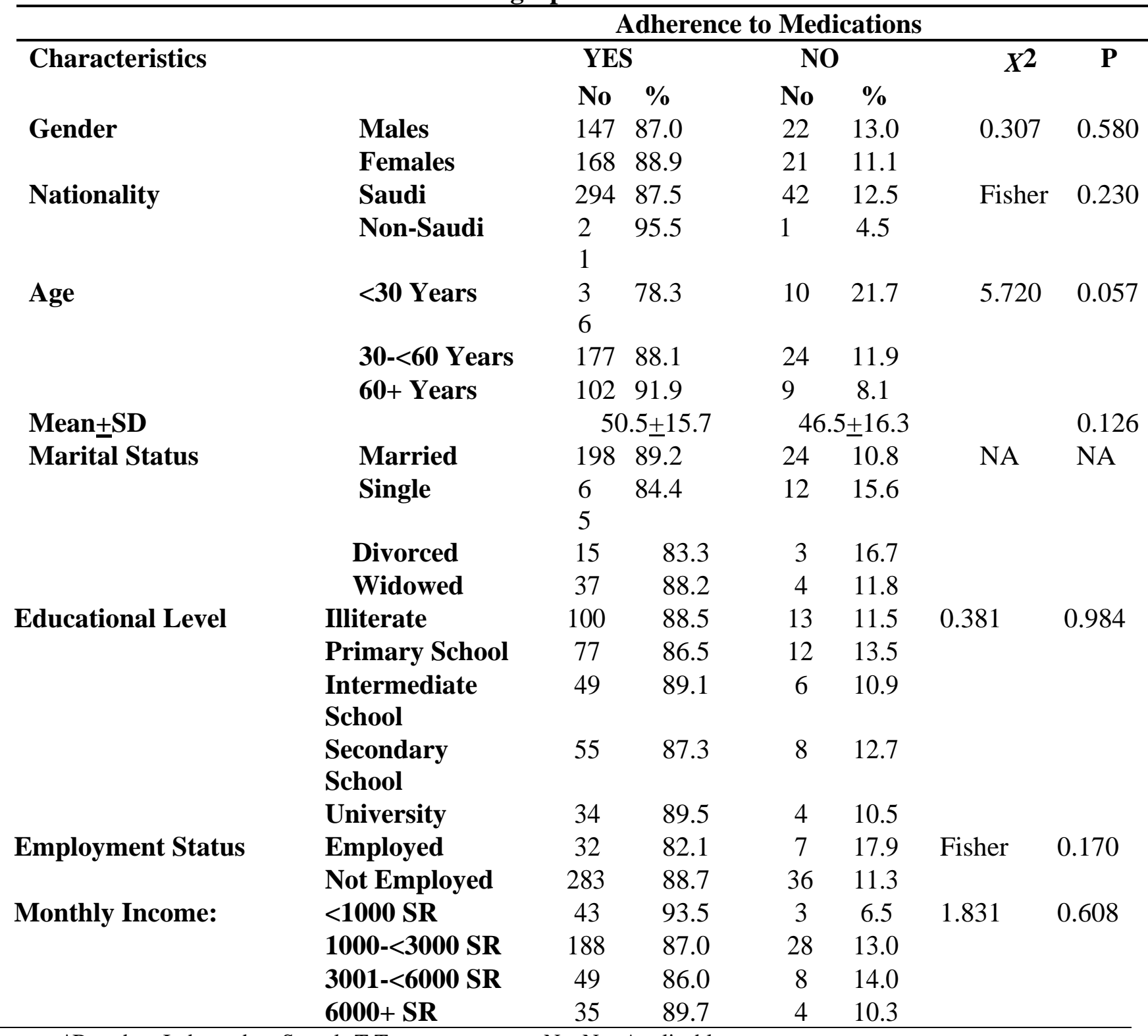

*Based on Independent Sample T Test

Na: Not Applicable

Table 8: Adherence of The Patients to Medication Recommendations According to Their Clinical Background

\begin{tabular}{|c|c|c|c|c|c|c|c|}
\hline \multirow{3}{*}{ Characteristics } & & \multicolumn{5}{|c|}{ Adherence to Medications } & \multirow{3}{*}{$\mathbf{P}$} \\
\hline & & \multicolumn{2}{|c|}{ YES } & \multicolumn{2}{|c|}{ NO } & \multirow[t]{2}{*}{$X^{2}$} & \\
\hline & & No & $\%$ & No & $\%$ & & \\
\hline \multirow[t]{2}{*}{ Duration of Dialysis } & $<60$ Months & 149 & 84.7 & 27 & 15.3 & 4.122 & 0.042 \\
\hline & 60+ Months & 164 & 91.6 & 15 & 8.4 & & \\
\hline \multirow{2}{*}{$\begin{array}{l}\text { Main Cause of Renal } \\
\text { Failure }\end{array}$} & Hypertension & 71 & 89.9 & 8 & 10.1 & 3,500 & 0.174 \\
\hline & $\begin{array}{l}\text { Diabetes } \\
\text { Mellitus }\end{array}$ & 77 & 92.8 & 6 & 7.2 & & \\
\hline
\end{tabular}




\begin{tabular}{|c|c|c|c|c|c|c|c|c|}
\hline \multirow{3}{*}{$\begin{array}{l}\text { Previous } \\
\text { Transplant }\end{array}$} & \multirow[b]{3}{*}{ Kidney } & \multirow{3}{*}{$\begin{array}{l}\text { Others } \\
\text { Yes }\end{array}$} & & & \multicolumn{4}{|c|}{ DOH 10.55031/1JVISS.314002 } \\
\hline & & & 167 & 85.2 & 29 & 14.8 & & \\
\hline & & & 21 & 95.5 & 1 & 4.5 & Fisher & 0.254 \\
\hline & & No & 295 & 87.5 & 42 & 12.5 & & \\
\hline Diagnosed & with & Yes & 32 & 88.9 & 4 & 11.1 & Fisher & 0.560 \\
\hline $\begin{array}{l}\text { Psychiatric } \\
\text { Illness }\end{array}$ & & No & 283 & 87.9 & 39 & 12.1 & & \\
\hline
\end{tabular}

Table 8 shows that the higher the duration of dialysis the more likely the patient will be adherent to medications' recommendations; the percentage of non-adherent patients decreased significantly from $15.3 \%$ among patients with dialysis for less than 60 months to $8.4 \%$ among patients with dialysis for $60+$ months $\mathrm{p}<0.05$. Otherwise, although there was relatively higher adherence frequencies among diabetic patients, those with kidney transplant and who have history of psychiatric illnesses, these differences are not statistically significant $p>0.05$.

\section{Discussion}

The results of the current study came in line with what was previously addressed that, among the ESRD population, older patients are more likely to be adherent to treatment (C Kugler et al., 2005; Kutner, Zhang, McClellan, \& Cole, 2002) especially to fluid restrictions' recommendations. Same findings were elaborated in other studies (B et al., 2007; KA, KS, YM, \& SB, 2008; NG, 2001), this notion could be explained by the argument that older patients may have more structured lifestyle that accommodates the demands of the treatment regimen while younger patients may perceive themselves as less vulnerable to negative health outcomes ${ }^{(\mathrm{NG}, 2001)}$.

The significantly higher non-adherence rates to fluid restriction in young patients are similar to findings in other studies (V. H, B, A, S, \& G, 2001; C Kugler et al., 2005; Takaki et al., 2003). The relatively low level of adherence among this group of patients had been partially attributed to the feeling of independence which is usually intense in young people, this feeling lead to possible disregard of health instructions, and they could have under estimation for the adverse consequences that might result from non-adherence ${ }^{(\mathrm{NG}, 2001)}$. For this reason, it has been ascertained that younger patients under dialysis could have poorer quality of life in the future and higher mortality rates (NG, 2001; Takaki et al., 2003).

Similarly, older patients had been found more adherent to dietary recommendations with phosphorus and sodium restrictions, these findings came in congruence with what was found among Korean HD patients (Y.-J, K.-S, Y.-R, J.-S, \& J.-B, 2009). The same was also reported by Park et al (2008) who pointed that older patient are usually having lower appetite and limited physical activity, therefore their need and graving to food is more less than the younger patients, accordingly the older patients are more likely to be adherent to dietary restrictions (KA et al., 2008).

Even when controlled for other factors, age was found to be significantly associated independently with the level of adherence of the HD patient to diet that showed itself in IDWG, this notion was introduced by Lisa Mellonmail et al in 2012 who studied factors influencing adherence among Irish HD patients and by regression analysis it was revealed that younger patients had poorer adherence, that was attributed to the claim that younger patients may experience greater difficulty integrating complex treatment demands into their lifestyles, and non-adherence may be a consequence of the severe lifestyle limitations imposed by the HD treatment regime ${ }^{\text {(Mellonemail et al., 2013). }}$ 


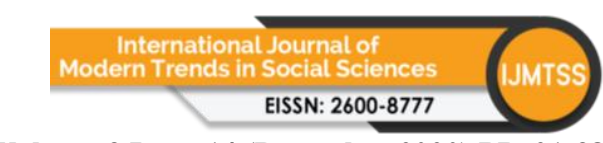

Volume 3 Issue 14 (December 2020) PP. 21-38

DOI 10.35631/IJMTSS.314002

Patients with longer duration on HD (60 months and greater) were found to be less adherent to fluid restrictions recommendations (P:0.011), Although that this finding comes in accordance with other studies (M \& W, 1999; PL et al., 2000; SH \& A, 2002), these studies draw the attention that there is no single convincing explanation for this change of adherence level of the patients being more less along time. Nevertheless, Yoke Mun Chan et al (2012) suggested that it is likely that the long duration of dependence on dialysis (length of time on dialysis) may cause HD patients to be accustomed to the restrictions imposed by the disease that might create false perception of better compliance than they actually do. Secondly, the use of clinical data for example serum potassium and phosphorus as the direct measures of dietary compliance could be misleading as these clinical data may also be affected by factors such as dialysis adequacy, medication and other factors yet to be identified (Chan et al., 2012).

Another plausible explanation is that end stage renal disease patients may be more eager to change their dietary and fluid intake habits to meet the requirement of a newly received lifesaving HD treatment. However as time passes, these patients may feel bored and easily get frustrated with the need to comply with long lists of restrictions (LW, SF, \& SW, 2010).

From another perspective, it had been postulated that patients new to dialysis treatment may receive more social support, therefore they exhibit higher degree of compliance (LW et al., 2010). However, over the long run, it may be difficult for patients to resist the wide variety of foods and fluids. In view of this, it had been addressed that healthcare providers should identify the individual's perceived barrier, explore patients' willingness and readiness to make changes to their dietary and fluid habits to achieve the optimum effect of compliance (Chan et al., 2012).

On the other hand, this study showed that subjects with longer duration on HD (60 months and greater) were more adherent to medications (p:0.042), that could be attributed to notion that with time, the patients are becoming more knowledgeable and would having clear understanding of medications instructions about importance, timing, dose of medications; these information are expected to be reinforced by nurses and physicians about the value of medications and importance of incorporating drug administrations into patients daily lives, that will ultimately make patients with longer duration on HD to be more adherent to medications.

The current study showed that male are more adherent to diet restrictions than female (P:0.048) which is consistent with other international study carried out by Saran et al (2003) (Saran et al., 2003). Possible explanation is that in Saudi people culture female usually less educated than male, so, they are more adherent than female. Other possible explanation is that in Saudi community, females are usually stay in homes most of their time in contrast to males who are usually spend most of their time outside homes (in work, recreation, etc..), therefore, females have longer time for being close to food and available facilities for preparing meals.

On the other side, and in contradiction to our findings, a study conducted by Yoke et al (2012) revealed that male patients were more likely to be non-adherent (Chan et al., 2012); their explanation was that women are more likely to be health conscious than men and this explain how gender differences in adherence may benefit patients concerning health outcomes in the long run.

Our study showed that being married is an important factor in adherence to fluid restriction (p:0.001). Similar findings were found in a study conducted by Kelly et al (2009), through a review of the published literature from 1948 to 2001, they could argue that marital status and living with another person (for adults) increase adherence modestly (Zolnierek \& DiMatteo, 2009). Copyright $\odot$ GLOBAL ACADEMIC EXCELLENCE (M) SDN BHD - All rights reserved 
Kutner (2001) and Rosner(2006) reported that spouses have positive effects on compliance

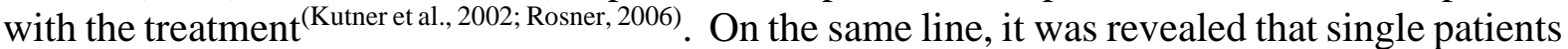
are less likely to be adherent than married patients (Sherry, Nancy, \& Nelda, 2013), which reflect the effect of spouse on increasing adherence of the patient to medical instructions and recommendations.

Our study showed that hypertensive and diabetic patients are significantly more likely to adhere to fluid restriction if compared to those with other chronic diseases; these differences are statistically significant $p<0.05$. This finding is inconsistent with what was observed by a study conducted in USA, where the researchers found that there was no significant association between the presence of diabetes mellitus and changes in IWG (adherence to fluid restrictions $)^{(\text {Kimmel, Varela, Peterson, \& al, 1999) }}$. This notion could be presumably attributed to the claim that diabetic and hypertensive patients may be more afraid from complications and its consequences more than non-diabetic and non-hypertensive; so, they are more adherent to their fluid restrictions recommendations.

Saudi patients were found to be more adherent to fluid restriction recommendations than nonSaudis (p:0.039). No other researches available concerned about exploring association between nationality and adherence. However, this low adherence among non-Saudi may be attributed to poor language communication between patients and healthcare professional staff especially in misunderstanding the medical instructions about changing adherence behavior. Other possible explanation is that non-Saudi patients are usually having a lower socioeconomic status than Saudi. The association between socioeconomic status and level of adherence had been disclosed by Sherry et al (2013) who found that low income patients are less adherent to fluid restrictions than high income patients ${ }^{\text {(Sherry et al., 2013). }}$

The main limitation of this study is the inherited drawback of the cross-sectional being unable to detect causal relationship between variables. A longitudinal design might be better to display changes of over time.

In conclusion, younger ( $<30$ years), unmarried, non-Saudis, patients with chronic diseases other than HTN\&DM and those with long dialysis duration (60+ months) were found more likely to be non- adherent to fluid. Females patients and those with short dialysis duration $(<60$ months) were found more likely to be non-adherent to diet and medications, respectively. These groups warrant special attention and support to improve their adherence behavior.

The findings from this study can be used as a base for designing an intervention aimed to increase the adherence to treatment in ESRD patients who are undergoing HD, used as a database for further studies in other parts of Saudi Arabia and internationally, assisting in planning screening programs to detect high risk patients, enabling the government and other health agencies to establish strategies and national health care approaches to ameliorate the NA problem.

\section{References}

B, K., K, C., \& S, K. (2007). Nonadherence with diet and fluid restrictionsand perceived social support in patients receiving hemodialysis. J Nurs Scholarsh, 39(3), 243-248.

Chan, Y. M., Zalilah, M. S., \& Hii, S. Z. (2012). Determinants of Compliance Behaviours among Patients Undergoing Hemodialysis in Malaysia. PLoS ONE, 7(8), e41362. doi: 10.1371/journal.pone.0041362 
CL, D., M, H., V, W., \& F, P. (2004). Knowledge of dietary restrictions and the medical consequences of noncompliance by patients on hemodialysis are not predictive of dietary compliance. J Am Diet Assoc, 104(1), 35-41.

Denhaerynck, K., Manhaeve, D., Dobbels, F., Garzoni, D., Nolte, C., \& Geest, S. D. (2007). Prevalence and Consequences of Nonadherence to Hemodialysis Regimens. Am J Crit Care, 16(3), 222-225.

DL, K., E, B., S, H., D, L., JL, J., \& FauciAS. (2004). Harrison's Principle of Internal Medicine. 16th ed. New York: MC Grow Company.

Eida, M. (2010). Chronic hepatitis $\mathrm{C}$ genotype 4 treatment in chronic haemodialysis patients: A retrospective study. Arab Journal of Gastroenterology, 11(2), 83-87.

Green, J. A., Mor, M. K., Shields, A. M., Sevick, M. A., Arnold, R. M., Palevsky, P. M., \& al, e. (2013). Associations of Health Literacy With Dialysis Adherence and Health Resource Utilization in Patients Receiving Maintenance Hemodialysis. American Journal of Kidney Diseases, 62(1), 73-80.

H, S., B, H., \& H, S. (2009). Adherence to prescribed oral medication in adult patients undergoing chronic hemodialysis: a critical review of the literature. Eur J Med Res, 14(5), 185-190.

H, V., B, M., A, J., S, R., \& G, E. (2001). Thedialysis diet and fluid non-adherence questionnaire: Validity testing of a self-report instrument for clinical practice. Journal of Clinical Nursing,, 10(707), 715.

Hecking, E., Bragg-Gresham, J. L., Rayner, H. C., Pisoni, R. L., Andreucci, V. E., Combe, C., $\&$ al, e. (2004). Haemodialysis prescription, adherence and nutritional indicators in five European countries: results from the Dialysis Outcomes and Practice Patterns Study (DOPPS). Nephrol Dial Transplant, 19(1), 100-107.

JM, L.-G., M, V., R, J., P, R.-B., \& R, P.-G. (2005). Interdialytic weight gain as a marker of blood pressure, nutrition, and survival in hemodialysis patients. KidneyInternational, 67(Suppl 93), S63-S68.

KA, P., KS, C., YM, S., \& SB, K. (2008). Comparison of dietary compliance and dietary knowledge between older and younger Korean hemodialysis patients. J Ren Nutr, 18(5), 415-423.

Kim, Y. (2010). Relationship between Illness Perceptions, Treatment Adherence, And Clinical Outcomes in Patients On Maintenance Hemodialysis. Nephrol Nurs J, 37(3), 271-281.

Kim, Y., S.Evangelista, L., R.Phillips, L., Carol Pavlish, \& D.Kopple, J. (2010). The End-Stage Renal Disease Adherence Questionnaire (ESRDAQ):Testing The Psychometric Properties in Patients Receiving In-Center Hemodialysis. Nephrol Nurs J, 37(4), 377393.

Kimmel, P. L., Varela, M. P., Peterson, R. A., \& al, e. (1999). Interdialytic weight gain and survival in hemodialysis patients: Effects of duration of ESRD and diabetes mellitus. Kidney International, 57, 1141-1151. doi:10.1046/j.1523-1755.2000.00941.x

KM, C., MH, B., JP, K., \& NW, L. (1982). Psychosocial factors affecting adherence to medical regiments in a group of hemodialysis patients. Medical Care, 20(6), 567-580.

Kugler, C., Maeding, I., \& L.Russell, C. (2011). Non-adherence in patients on chronic hemodialysis: an international comparison study. J NEPHROL, 24(03), 366-375.

Kugler, C., Vlaminck, H., Haverich, A., \& Maes, B. (2005). Nonadherence with diet and fluid restrictions among adults having hemodialysis. Journal of Nursing Scholarship, 37(1), 25-29.

Kutner, N. G., Zhang, R., McClellan, W. M., \& Cole, S. A. (2002). Psychosocial predictors of non-compliance in haemodialysis and peritoneal dialysis patients. Nephrology Dialysis Transplantation, 17(93), 99. 
Lacson Jr, E., \& Hakim, R. M. (2011). The 2011 ESRD prospective payment system: perspectives from Fresenius Medical Care, a large dialysis organization. American Journal of Kidney Diseases, 57(4), 547-549.

Latham, C. (1998). Obstacles to achieving adequate dialysis dose: Compliance, education, transportation, and reimbursement. American Journal of Kidney Diseases, 32(6), S93S95.

Lee, S.-h., \& Molassiotis, A. (2002). Dietary and fluid compliance in Chinese hemodialysis patients. International Journal of Nursing Studies, 39(7), 695-704.

Leggat Jr, J. E., Orzol, S. M., Hulbert-Shearon, T. E., Golper, T. A., Jones, C. A., Held, P. J., $\&$ al, e. (1998). Noncompliance in hemodialysis: Predictors and survival analysis. American Journal of KidneyDiseases, 32(1), 139-145.

LK, T., RG, S., PC, M., DL, R., RF, V., \& CG, M. (2001). Identification of the factors associated with compliance to therapeutic diets in older adults with end stage renal disease. J Ren Nutr, 11(2), 80-89.

LW, L., SF, T., \& SW, C. (2010). Self-reported adherence to a therapeutic regimen among patients undergoing continuous ambulatory peritoneal dialysis. J Adv Nurs. 2010 Apr;66(4):763-73. doi, 66(4), 763-773. doi: 10.1111/j.1365-2648.2009.05235.x.

M, O., \& W, C. (1999). Dietary behaviors and sources of support in hemodialysis patients. Clin Nurs Res, 8(4), 302-314.

Mellonemail, L., Regan, D., \& Curtis, R. (2013). Factors influencing adherence among Irish haemodialysis patients. Patient Education and Counseling, 92(1), 88-93.

ML, U., IV, E., NE, F., NR, P., \& KB, M. (2005). Choices for Healthy Outcomes in Caring for End-Stage Renal Disease (CHOICE) Study. Skipped treatments, markers of nutritional nonadherence, and survival among incident hemodialysis patients. Am J Kidney Dis, 46(6), 1107-1116. doi: 10.1053/j.ajkd.2005.09.002. [PubMed] [Cross Ref]

(NKF)., N. K. F. (2002). K-DOQI (kidney disease outcome quality initiative) clinical practice guidelines for clinical kidney disease: Evaluation, classification, and stratification. ation, classification, and stratification. American Journal of Kindney Diseases, 39(Suppl.1), S 45-S 75.

NG, K. (2001). Improving compliance in dialysis patients: does anything work? Semin Dial, 14(5), 324-327.

Organization, W. H. (2003). Defining adherence. Adherence to long-term therapies: evidence for action. Geneva: WHO, 16-28.

PL, K., MP, V., RA, P., KL, W., SJ, S., S, A., \& al., e. (2000). Interdialytic weight gain and survival in hemodialysis patients: effects of duration of ESRD and diabetes mellitus. Kidney Int, 57(3), 1141-1151.

PV, B., \& E, S. (2003). Adherence to long-term therapies: evidence foraction. J Nurs Scholarsh, 35(3), 207.

Rosner, F. (2006). Patient noncompliance: Causes and solutions. TheMount Sinai Journal of Medicine, 73(2), 553-559.

Saran, R., Bragg-Gresham, J. L., Rayner, H. C., Goodkin, D. A., Keen, M. L., Van Dijk, P. C., $\&$ al., e. (2003). Non adherence in hemodialysis: associations with mortality, hospitalization and practice patterns in the DOPPS. Kidney Int, 64(1), 254-262.

SH, L., \& A, M. (2002). Dietary and fluid compliance in Chinese hemodialysis patients. Int J Nurs Stud, 39(695), 704.

Sherry, I. B., Nancy, P., \& Nelda, P. W. (2013). Variation in hemodialysis patient compliance according to demographic characteristics. Social Science \& Medicine, 37(8), 10351043 
SI, B., N, P., \& NP, W. (1993). Variation in hemodialysis patient compliance according to demographic characteristics. Social Science \& Medicine, 37(8), 1035-1043.

Takaki, J., Nishi, T., Shimoyama, H., Inada, T., Matsuyama, N., Sasaki, T., \& al, e. (2003). Associations and interactions of age, sex, and duration of hemodialysis with compliance in uremic patients. Dialysis \& Transplantation,, 32(1), 12-16.

Transplantation, S. C. f. O. (2012). Dialysis in the Kingdom of Saudi Arabia. Saudi J Kidney Dis Transplant, 24(4), 853-861.

Y, K., \& LS, E. (2010). Relationship between illness perceptions, treatment adherence, and clinical outcomes in patients on maintenance hemodialysis. Nephrol Nurs J, 37(3), 271280.

Y.-J, S., K.-S, C., Y.-R, P., J.-S, B., \& J.-B, L. (2009). Depression, Symptoms and the Quality of Life in Patients on Hemodialysis for End-Stage Renal Disease. Am J Nephrol, 29, 36-42. doi:10.1159/000150599

Zolnierek, K. B. H., \& DiMatteo, M. R. (2009). Physician Communication and Patient Adherence to Treatment: A Meta-analysis. Med Care, 47(8), 826-834. 